\title{
Manejo sustentável na produção de aves caipiras de postura: experiência de estágio na comunidade de Salinas
}

Este artigo trata acerca dos métodos alternativos para a redução de custos na criação de aves caipiras na comunidade de Salinas, zona rural de Senhor do Bonfim Bahia. O trabalho se dá a partir da identificação do manejo de aves já utilizados nessa comunidade e debate sobre os métodos alternativos para alimentação dos animais que reduzam o custo de produção, fazendo com que o produtor consiga uma renda maior na comercialização do seu produto. A metodologia utilizada foi observações, oficinas e entrevistas com os produtores. No geral, os criadores e produtores utilizam na alimentação das aves a ração comercial composta por milho, farelo de trigo, farelo de soja, fontes de cálcio, fontes de fósforo, premixes e entre outros, essa alimentação reflete no custo alto de produção das aves, já que de acordo com o período, o preço de parte desses ingredientes utilizados na formulação da ração torna inviável a produção. Os métodos alternativos de alimentação das aves surgem para reduzir o custo de produção e consequentemente o custo do produto final. Nesse estágio, o método alternativo de alimentação em destaque é construção de leiras para produção de hortaliças, essas podem ser beneficiadas pelo aviário através dos resíduos utilizados como adubos, nesse sistema, os aviários também se beneficiam, sendo os restos vegetais das hortaliças utilizados como fontes de alimentação alternativa das aves.

\section{Sustainable management in the production of laying free-range birds: internship experience in the Salinas community}

\begin{abstract}
This article deals with alternative methods to reduce costs in the creation of free-range birds in the community of Salinas, rural area of Senhor do Bonfim, Bahia. The work takes place from the identification of the management of birds already used in this community and debate about the alternative methods for feeding the animals that reduce the production cost, making the producer obtain a higher income in the commercialization of his product. The methodology used was observations, workshops and interviews with producers. In general, breeders and producers use commercial feed composed of corn, wheat bran, soybean meal, calcium sources, phosphorus sources, premixes, and poultry feed, among others, this feed reflects the high cost of poultry production, since according to the period, the price of part of these ingredients used in the formulation of the feed makes production unfeasible. Alternative methods of feeding the birds appear to reduce the cost of production and consequently the cost of the final product. In this stage, the alternative method of feeding highlighted is the construction of windrows for the production of vegetables, these can be benefited by the aviary through the residues used as fertilizers, in this system, the aviaries also benefit, being the vegetable remains of the vegetables used as sources alternative feeding of birds.
\end{abstract}

Keywords: Poultry farming; Alternative feeding methods; Cost reduction; Vegetables.

\section{Topic: Zootecnia}

Reviewed anonymously in the process of blind peer.
Received: $15 / 08 / 2019$

Approved: 11/11/2019
Thales de Araújo Barboza (iD

Instituto Federal Baiano, Brasil

http://orcid.org/0000-0001-7093-6179

thales.ba.tb@gmail.com

Yane Gama da Silva

Instituto Federal Baiano, Brasil

http://lattes.cnpq.br/6287071164744153

http://orcid.org/0000-0001-7905-5036

yanegama21@gmail.com

Gleisy Vieira Campos (iD)

Universidade Federal de Uberlândia, Brasil http://lattes.cnpq.br/1819156418353225 http://orcid.org/0000-0002-5588-5606

gleisy.campos@ifbaiano.edu.br
Referencing this:

BARBOZA, T. A.; SILVA, Y. G.; CAMPOS, G. V.. Manejo sustentável na produção de aves caipiras de postura: experiência de estágio na comunidade de Salinas. Agriculturae, v.1, n.2, p.18-24, 2019. DOI: http://doi.org/10.6008/CBPC2674-645X.2019.002.0002 


\section{INTRODUÇÃO}

O presente trabalho traz abordagens da experiência de estágio supervisionado que ocorreu na SEDAF - Secretaria de Agricultura Familiar no Município de Senhor do Bonfim - BA, no período de 22/10/2019 a 17/12/2019, no qual os pontos de estudo foram às práticas sustentáveis de manejo, produção e comercialização que possibilitem a redução de custos na criação de aves caipiras na comunidade de Salinas.

O tema proposto surge da necessidade da comunidade e a partir da sugestão da equipe da SEDAF em que o estágio fosse realizado nessa comunidade, pois os agricultores familiares de Salinas foram contemplados com um projeto governamental do Bahia produtiva por meio da SEDAF, tendo em vista à implantação de aviários nessa comunidade a ideia desse projeto se fundamentou na redução dos custos de produção na criação de aves caipiras utilizando técnicas sustentáveis de manejo, produção e comercialização.

Assim, os objetivos principais deste trabalho foram à identificação das técnicas de manejo sustentável utilizadas pela comunidade na criação de aves e avaliação da reação/participação dos produtores diante de uma oficina e construção de canteiros para produção de hortaliças, cujos restos vegetais poderão ser utilizados como alimentação alternativa para aves. Para tanto, utilizou-se a pesquisa-intervenção e como estratégias e instrumentos metodológicos, observações, rodas de conversas, oficinas e entrevistas semiestruturadas com agricultores familiares, possibilitando assim, diálogo, interação e troca de conhecimentos entre os participantes.

Dessa forma, no presente artigo, apresentamos o relato e estudo reflexivo, sobre a experiência de estágio, a partir da análise das atividades desenvolvidas na comunidade, tendo em vista as observações das interações na ação pratica da vivência do estágio, salientando a importância da compreensão dos produtores no que tange a redução de custos no manejo produtivo de aves caipira de forma sustentável. No decorrer do artigo, abordaremos no primeiro subtítulo informações sobre alternativas que possibilitem a redução de custo no manejo alimentar das aves e na sequência faremos uma análise reflexiva sobre a experiência do estágio, abordando os aspectos relevantes para nossa formação profissional.

\section{DISCUSSÃO TEÓRICA}

\section{A cadeia produtiva de avicultura: alternativas alimentares sustentáveis}

O estado da Bahia, vem se destacando no cenário da cadeia produtiva da avicultura brasileira, hoje, estima-se que apenas nesse estado estejam localizadas mais de 485 granjas, e nessas, mais de 32 milhões de aves, segundo o censo agropecuário de 2017. A avicultura baiana hoje ocupa o 10ㅇ lugar no cenário nacional referente a quantidade de cabeças de aves. Se tratando de estabelecimentos, essa ocupa o 1 o lugar. Na Bahia, lideram o ranking de rebanho os municípios de Conceição de Feira, Barreiras e Feira de Santana, com um rebanho total de mais de 800 mil cabeças.

Em relação à alimentação das aves de acordo com Rostagno et al. (2005), os ingredientes mais importantes utilizados como base das rações comerciais são o milho como fonte energética e o farelo de soja que é fonte proteica. Além deles, existem também o farelo de trigo, sal, fontes de cálcio e de fósforo, 
premixes minerais entre outros.

Geralmente, na criação de galinhas caipiras são utilizados outros tipos de alimentos na alimentação das aves para suprir as exigências de fontes protéicas, energéticas e minerais, necessários ao organismo animal, como: hortaliças e restos de culturas, frutas, verduras, gramíneas, plantas nativas, PANCs (plantas alimentícias não convencionais), cana-de-açúcar e seus subprodutos, resíduos industriais e outros, sendo esses considerados alimentos alternativos, e que consequentemente reduzem os gastos na produção.

No manejo sustentável dos aviários devem ser aproveitados todos os elementos disponíveis possíveis, nesse contexto segundo Sales (2005), o esterco de aves é um dos materiais que podem ser aproveitados, pois é uma fonte de grande importância para a adubação orgânica devido aos elevados valores de nitrogênio e fósforo em sua composição. De todos os estercos, o de galinha é o mais mineralizado. Na agricultura orgânica esta prática assume grande importância, pelo papel que os adubos orgânicos representam na manutenção da fertilidade do sistema (SALES et al., 2011; ARAUJO et al., 2007).

O melhor uso para o esterco de galinha na olericultura é na forma de compostagem orgânica. Quando é deixado curtir ou armazenado puro, as perdas de nitrogênio por volatilização podem ser quase totais (KHATOUNIAN, 2001). Sendo assim, a compostagem é um dos principais métodos utilizados no meio agropecuário para a reciclagem de resíduos, ou seja, melhor aproveitamento dos materiais provenientes desse meio. A compostagem é feita de forma aeróbica para que haja a maturação dos resíduos presentes aumentando assim a mineralização das substancias orgânicas.

Dessa forma, é possível essa consorciação de produção de canteiros de hortaliças, e outras plantas com a criação de aves, pois os resíduos produzidos pelas mesmas poderão ser utilizados como adubo nos canteiros, e os restos vegetais das hortaliças e outros cultivos, serão fonte de alimentação alternativa para as aves, formando assim um processo vantajoso para o produtor em relação a economia nos custos de produção da ração.

\section{METODOLOGIA}

Utilizamos como elementos metodológicos para a execução das análises da experiência de estagio, observações participativas na sede da SEDAF - Secretaria de Desenvolvimento da Agricultura Familiar de Senhor do Bonfim, rodas de conversas entre o corpo institucional e com os produtores também, entrevista semiestruturada, direcionada para os produtores da comunidade, segundo Manzini (1991) a entrevista semiestruturada está baseada em um assunto sobre o qual confeccionamos um roteiro com perguntas principais, complementadas por outras questões inerentes às circunstâncias momentâneas à entrevista. Nesse tipo de entrevista podem surgir informações de forma mais livre e as respostas não estão condicionadas a uma padronização de alternativas. Dessa maneira, objetivamos uma aproximação entre os sujeitos, conhecimento da realidade local e observação do tipo de criação e manejo alimentar das aves que os produtores utilizam. Também desenvolvemos uma oficina para analise acerca da experiência do estágio. As oficinas são capazes de proporcionar aprendizagens mais completas, pois valoriza a construção do conhecimento de forma participativa e questionadora, baseada em situações do cotidiano do aluno 
(NASCIMENTO, 2007).

No decorrer da oficina observamos um momento de interação com os produtores, sendo possível alcançar alguns dos nossos objetivos, que foi a identificação dos principais alimentos fornecidos para as aves que eles criam atualmente em suas propriedades, difundir alternativas alimentares sustentáveis para as aves.

\section{Relato da vivência do estágio}

Neste relato daremos ênfase aos elementos metodológicos abordados anteriormente para analises e considerações da nossa experiência de estágio. Iniciamos o período de estágio com observações participativas na sede da SEDAF - Secretaria de Desenvolvimento da Agricultura Familiar de Senhor do Bonfim, a princípio realizamos uma entrevista com o Diretor da secretaria Joaquim Ferreira Barros, que nos introduziu sobre os projetos vinculados e apoiados pela SEDAF, às comunidades assistidas, as contribuições sociais, enfim, todas as atividades que a secretaria participa atualmente. Dessa maneira, foi possível compreender melhor a atuação e importância da secretaria para a população do município de Senhor do Bonfim. Diante disso, o diretor nos sugeriu a ideia de desenvolvermos nosso estágio na comunidade de Salinas, cuja mesma foi beneficiada com o projeto de implantação de aviários. Dessa forma, foi realizada uma visita a comunidade buscando observar os aspectos relevantes para a realização do estágio na mesma.

Assim, levamos para a comunidade uma entrevista semiestruturada, realizando a mesma com os produtores, nessa entrevista, os produtores foram questionados sobre a criação de aves caipira na sua propriedade antes da instalação dos aviários e os métodos de manejo alimentar dos animais entendendo os saberes empíricos dos beneficiários. Nesse tipo de entrevista podem surgir informações de forma mais livre e as respostas não estão condicionadas a uma padronização de alternativas. De tal modo, foi possível a identificação das técnicas de manejo sustentáveis utilizadas pelos produtores na criação de aves e as formas de produção e controle que eles utilizam.

Dessa maneira, conseguimos identificar as práticas de manejo utilizadas pelos produtores e, além disso, conseguimos uma interação com cada produtor visto que, as entrevistas ocorreram nas propriedades individualmente, possibilitando um melhor diálogo e socialização das ações futuras do projeto.

Outra analise desenvolvida acerca da experiência do estágio foram construídas a partir de uma oficina com os produtores na comunidade de Salinas. Assim, foi possível a adoção de diversas estratégias para que houvesse um processo de ensino mais dinamizado. A partir desse momento de interação com os produtores foi possível à identificação dos principais alimentos fornecidos para as aves que eles criam atualmente em suas propriedades, para isso montamos um quadro com os insumos que geralmente são consumidos pelas aves e questionamos quais os insumos utilizados.

Através da análise da imagem acima é possível evidenciar que os alimentos mais utilizados pelos produtores da comunidade de Salinas para o consumo das aves são os restos vegetais e o farelo de milho, ou seja, os insumos mais comuns e mais acessíveis aos produtores. O quadro foi preenchido através das respostas dos produtores pelo uso desses insumos na alimentação das aves. 


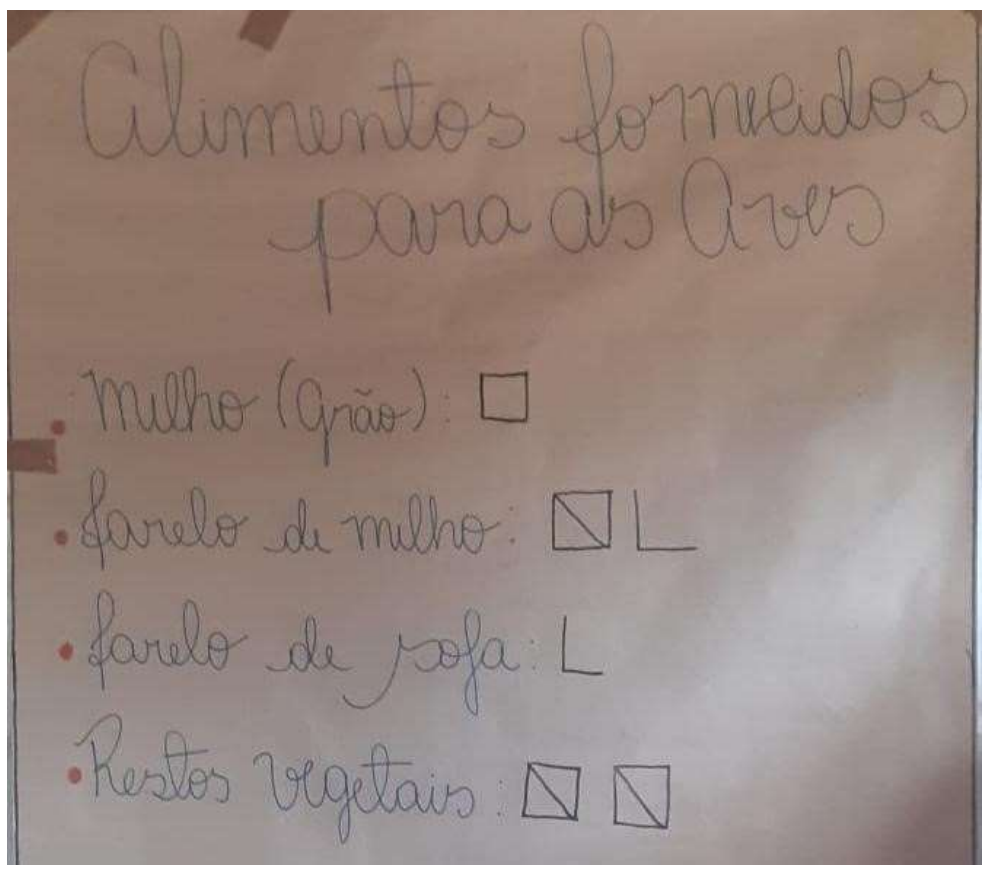

Fotografia 1: Resposta dos produtores a enquete oral.

Posteriormente, realizamos também durante a oficina a dinâmica dos mitos e verdades, onde nós lançamos perguntas vinculadas ao tema e questionamos se eles consideravam mito ou verdade, os produtores demonstraram participação e envolvimento respondendo todas as pontuações. Algumas das referidas afirmações foram: a) a cor da casca do ovo determina qualidade e tipo de criação; b) os ovos não podem ser armazenados na porta da geladeira; c) galinhas botam mais de um ovo por dia; d) deve-se lavar todos os ovos antes de guarda-los. Os produtores responderam para a correspondente a) que era verdade, os mesmos afirmaram que a cor da casca interfere no interior do ovo, e nós informamos que isso é um mito, a aparência da casca não altera sua composição nutricional ou sua qualidade. Na b) disseram que era mito, e nós trouxemos informações importantes que eles ainda não tinham ciência, de que os ovos não devem ser armazenados na porta da geladeira, tendo em vista a variação de temperatura ao abrir e fechar a porta da mesma, ou seja, essa alternância de temperatura pode interferir na qualidade dos ovos. Essa conhecença foi de grande valia, visto que a maioria dos produtores armazenam os ovos na porta da geladeira. No quesito c) eles afirmaram que sim, porém, eles retrataram experiências cotidianas no qual algumas vezes as galinhas botam ovos com mais de uma gema, como citou dona Madalena 'minha galinha bota um ovo com duas gemas'. Nós partilhamos que isso é normal, e que pode acontecer as vezes, mas a galinha não põe mais de um ovo por dia. E no d) eles responderam que sim, nesse caso nós relatamos que não é o correto porque ao lavar os ovos é retirada uma película protetora da casca, o que favorece a entrada de micro-organismos deteriorantes no ovo, visto que sua casca é porosa.

Nesse momento os participantes puderam tirar suas dúvidas, compartilhar suas experiências com todos presentes, assim contribuindo para um momento de troca de saberes, contextualizando conhecimentos técnicos e empíricos, sendo um momento de muito aprendizado.

O último momento de ação participativa do estágio foi à elaboração de um canteiro para a produção de hortaliças, esses, são áreas destinadas à produção vegetal sendo de extrema importância para a 
horticultura já que o objetivo desse é fazer com que o local da horta esteja em condições de ser cultivado. Utilizando esse método de produção, os restos vegetais servirão como alimentação alternativa para as aves e contribuirá para redução dos custos com a ração dos animais e consequentemente o custo de produção para o produtor. Também foi uma etapa de muito aprendizado para todos, pois a maioria dos produtores já possuem canteiros em suas propriedades, o que facilitou o processo. Desse modo, observamos que essas ações participativas como oficinas são momentos oportunos para interação do grupo e potencializa a difusão de conhecimentos.

\section{CONCLUSÕES}

A realização do estágio foi uma grande oportunidade para aquisição de conhecimentos para nós enquanto futuros profissionais na área das ciências agrárias, visto que esse período nos permitiu uma aproximação com a realidade dos produtores e uma troca de experiências contribuindo para a difusão de saberes técnicos e empíricos.

Nesse período de estágio, foi possível a obtenção de muito conhecimento, começando pela amplitude do trabalho desenvolvido pela Secretaria de Agricultura Familiar, no qual atende muitas comunidades no Município de Senhor do Bonfim, auxiliando os produtores e dando subsídio para que consigam almejar seus objetivos. Diante disso, a secretaria em geral obteve um papel fundamental para que nós pudéssemos realizar esse trabalho, nos dando todo suporte para o desenvolvimento do nosso projeto e garantindo que o mesmo acontecesse com a maior fluência possível.

No decorrer do período de estágio conseguimos alcançar nossos objetivos projetados, por meio do desenvolvimento da oficina observamos um momento de interação com os produtores, possibilitando a identificação dos principais alimentos fornecidos para as aves que eles criam atualmente em suas propriedades, difundir alternativas alimentares sustentáveis para as aves, com o objetivo de reduzir os custos com a ração e tirar dúvidas referentes a produção de aves caipira de postura.

Assim, conseguimos realizar nossas analises e identificações por meio dos elementos metodológicos, conhecendo melhor a comunidade em geral e sua produção. Acreditamos que essa experiência foi de suma importância não somente para nós, mas também para os produtores que participaram, no qual se mostraram interessados em compartilhar suas experiências já adquiridas assim como dispostos e abertos a testar novas práticas de manejo para essa cadeia produtiva.

Por fim, concluímos que além disso essa prática nos agrega conhecimento, segurança e profissionalismo para estar em frente ao mercado de trabalho, prestando assistência técnica para produtores, desempenhando papéis que alicerçam o curso de licenciatura em ciências agrárias como ensino, pesquisa e extensão.

\section{REFERÊNCIAS}

ARAUJO, J. A.; SILVA, J. H. V.; AMÂNCIO, A. L. L.; LIMA, M. R.; LIMA, C. B.. Uso de aditivos na alimentação de aves. Acta Veterinaria Brasílica, v.1, n.3, p.69-77, 2007.
SALES, M. N. G.. Criação de galinhas em sistemas

agroecológicos. Vitória: Incaper, 2005. 
KHATOUNIAN, C. A.. A reconstrução ecológica da agricultura. São Paulo: Agroecológica, 2001.

MANZINI, E. J.. A entrevista na pesquisa social. Didática, São Paulo, v.26-27, p.149-158, 1991.

NASCIMENTO, M. S.. Oficinas pedagógicas: Construindo estratégias para a ação docente: relato de experiência. Rev. Saúde Com., v.3, n.1, p.8595, 2007.
ROSTAGNO, H. S.; ALBINO, L. F. T.; DONZELE, J. L.;

SAKOMURA, N. K.; PERAZZO, F. G.; SARAIVA, A.; TEIXEIRA, M. L.; RODRIGUES, P. B.; OLIVEIRA, R. F.; BARRETO, S. L. T.; BRITO, C. O.. Tabelas brasileiras para aves e suínos: composição de alimentos e exigências nutricionais. Viçosa: Universidade Federal de Viçosa, 2005.

A CBPC - Companhia Brasileira de Produção Científica (CNPJ: 11.221.422/0001-03) detém os direitos materiais desta publicação. Os direitos referem-se à publicação do trabalho em qualquer parte do mundo, incluindo os direitos às renovações, expansões e disseminações da contribuição, bem como outros direitos subsidiários. Todos os trabalhos publicados eletronicamente poderão posteriormente ser publicados em coletâneas impressas sob coordenação da Cognitionis Publishing, da Companhia Brasileira de Produção Científica e seus parceiros autorizados. Os (as) autores (as) preservam os direitos autorais, mas não têm permissão para a publicação da contribuição em outro meio, impresso ou digital, em português ou em tradução. 